learninge and merite to be a member of their Societie who on all occasions so kindlie remembers them. They heartilee wish you all good health that you may further advance the knowledge of Natural Historie and long continue ane ornament to your Profession. I am with all respect $\mathrm{Sr}$,

Your Most Humble,

Edinburgh

Octrb. 9, 1725.
Most obedient Servant,

WM. PORTERFIELD.

The Much Honoured

Sir Hance Sloan Barntt

President of the College of Physicians

in London

\title{
THE SURGICAL TREATMENT OF CHRONIC GLAUCOMATOUS OCULAR HYPERTENSION*
}

BY

\section{HENRI LAGRANGE}

CHIEF OPHTHALMOLOGIST OF THE PARIS HOSPITALS AND OF THE A. DE ROTHSCHILD FOUNDATION

\section{I.-Definition of glaucomatous ocular hypertension}

Persons who present ocular hypertension following iritis, traumatism or tumour may have hard eyes and increased intraocular tension without necessarily being glaucomatous. While certain cases of this kind may be benefited by decompressive treatment, it is necessary to distinguish such conditions from true glaucoma and to define the signs of this affection, which illuminate its pathogeny and thus serve to direct its treatment.

(a) In glaucoma, ocular hypertension is an essential diagnostic sign, but one not exclusively peculiar to glaucoma. In the latter, the characteristic condition is not hypertension in itself, but the manner in which it occurs. Hypertension assumes a particular type in each of the several forms of glaucoma (prodromal glaucoma, chronic glaucoma with intermittent hypertension, chronic glaucoma with constant hypertension, irritative glaucoma, or acute glaucoma).

In prodromal glaucoma, ocular hypertension is of low degree. Subjectively, it is indicated by the appearance of a foggy or smoky veiling or by coloured arcs. Objectively, it presents pupillary

* For the thirty-third anniversary of subconjunctival and limbic sclerectomy. 
dilatation and a slight milky turbidity in the cornea, due to distension of this membrane. These signs are transitory, but may recur sooner or later and more or less frequently, according to the instability present in each case.

Chronic glaucoma with intermittent hypertension is the form anatomically defined by von Graefe as optic atrophy with excavation. In this clinical type, hypertension is as difficult to perceive as in the preceding form, because it is also transitory. Other signs of glaucoma, such as alterations in the visual field (scotomata or the nasal indentation), in light sensation, in the papilla and in the amplitude of accommodation, are often those which permit diagnosis.

Chronic glaucoma with constant hypertension is the clinical type which occurs most frequently. While the tonus is constantly high in this form, it is characteristically variable in degree. In this type of glaucoma, with moderate hypertension, violent crises may follow emotional conditions or surgical procedures; the eye may harden, so to speak, beneath the surgeon's knife. This instability is shown inversely by the remarkable efficacy of rest and the use of miotics. For illustrating this feature, I reported to the Ophthalmological Society of Paris on March 19, 1932, a group of cases of chronic glaucoma treated medically and remaining exposed to danger, since operative treatment might at any time be urgently necessary for the relief of conditions created by simple emotion or mere physical pain. ${ }^{1}$ The intermittent character thus occurs also in this type.

In irritative glaucoma, the ocular tension undergoes fluctuations which occur still more frequently. It is always evident, as shown by pupillary dilatation, changes in the corneal transparency, vascular congestion and a bluish and asphyxiated aspect in the episcleral circulation. This symptomatic group may prove deceptive for adherents of the inflammatory theory of glaucoma, who may mistakenly consider as signs of infection effects due only to passive lesions explicable solely by hypertension and the circulatory embarrassment which is secondary to it. The decisive test of the passive character of this pseudo-inflammatory condition consists in the possibility of operating surgically upon eyes of this type without inducing the complications which surely follow operating in the presence of acute iritis.

Acute glaucoma presents hypertension having from the onset the hardness of absolute glaucoma. It is related to Quincke's disease or to urticaria, and appears as if released by every stimulus possible when acting in predisposed tissues. In urticaria, all the occasional and determining causes constitute an urticarial summation of stimuli; there is similarly a glaucomatous summation producing the affection, in which we find humoral and colloido- 
plasmatic instability having the same paroxysmal character and doubtless depending upon a similar pathogenic process.

To summarise, glaucomatous hypertension presents the distinctive character of intermittence, which reveals its critical and paroxysmal nature.

(b) Alterations in the visual field in cases of glaucoma consist in nasal and inferior narrowing. This sign is notorious and requires stressing only in order to recall the fact that its constant and early appearance renders it characteristic of true glaucoma.

However, this is not the only change in the visual field. Scotomata, mentioned for the first time by Landesberg, in 1869, are of great symptomatic importance. Their early occurrence shows the developing disease. The commonest form, the paracentral scotoma of Bjerrum, is typical. It has the appearance of a crescent several degrees wide, in contact with the Mariotte spot and is incurved about the macula. Through fine elongation it extends to the limit of the peripheral visual field.

Angioscotometry has rendered the study of these incipient scotomata more precise. The Mariotte spot may become enlarged, and mild subjective signs are explained by conditions occurring in the more advanced stages, in which the scotoma becomes absolute and reaches the periphery of the visual field, which narrows and thus seems to meet the advancing scotoma. In this way indentations or notches are formed, which tend to surround the macula without invading it. Scotomata of this kind are never positive, not being projected and remaining identical both for white and for colours.

(c) Many writers have devoted special attention to the light and colour sense as affected by glaucoma, but the significance and value of changes in them have been clearly shown by Beauvieux ${ }^{2}$ and Delorme, ${ }^{3}$ who noted that " altered differential minimum, with normal light sense and perfect preservation of the colour sense" are the characteristic features of incipient glaucoma and who showed the pathognomonic value of these disturbances, which differ from those observed in other forms of optic atrophy. Minor signs of glaucoma consist of

The Bjerrum paracentral scotoma,

Loss of the differential light sense,

Preservation of the absolute light sense.

(d) The specific characters of the glaucomatous syndrome consist in somatic lesions of the deeper membranes, vessels and optic nerve.

In the retina, the typical changes consist of arteriosclerosis 
accompanied more or less distinctly by hypertrophy of the connective tissue. The vascular sclerosis present thus forms a predisposition to reflect rapidly the slightest changes in ocular tension.

In the uveal tract, the most evident lesions occur in the iris and ciliary body (sclerosis of the iris vessels and atrophy of the ciliary body), but it is necessary to stress the importance of changes in the irido-corneal angle corresponding to the reticular tissue of the canal of Schlemm. In glaucoma, gonioscopy reveals at this site an alteration which explains changes in the mechanism of ocular excretion, which consists of the Knies consolidation or union obliterating the angle of filtration, a change which is continually aggravated by the glaucomatous process, in which cytological débris is accumulated toward this angle. In this way the channel for normal escape of the interstitial liquid becomes occluded.

The optic nerve, showing papillary excavation on ophthalmoscopy, presents histologically lacunae related to the vascular changes. These lacunae have been described by Schnabel and studies made by Felix Lagrange $e^{4}$ prove that they result from secondary vascular changes dependent upon intra-ocular hypertonus. The papillary excavation which is shown by the ophthalmoscope to resemble a gourd, really terminates in a deep conical prolongation which penetrates between the vessels and pushes them apart. In view of these facts, vascular sclerosis does not appear to be the initial determining factor of true glaucoma, but rather to be a abiotrophy condition predisposing to vascular obliteration and favouring neuro-retinal atrophy.

\section{II.-Pathogeny of glaucomatous ocular hypertension}

From the various theories concerning this point, the opinions of three writers require special attention. They are Donders, Knies and Schnabel.

1. The tension retaining the aqueous humour within the eyeball seems to be specially governed by the action of the pars ciliaris retinae. In 1883, Boucheron presented to the French Ophthalmological Society an initial contribution to this point, contemporary with the work by Ranvier maintaining that the epithelial elements were superficial glands. These findings are confirmed by pathological histology. The presence in the ciliary body of adenomas, epitheliomas and carcinomas, described by F. Lagrange ${ }^{5}$ in his treatise on tumours of the eye, tends to affirm the existence of a differentiated tissue whose structure shows that it is actively concerned in elaborating the aqueous humour. 
The mechanism of this secretion may be explained by referring to the classical ideas concerning the physiology of the sympathetic. Without entering here upon this physiological question, we may recall the fundamental experiments upon the chorda tympani and the functional activity of the submaxillary gland. The sympathetic is the nerve of secretion, it increases ocular tension when stimulated and the decisive experiment by Pourfour du Petit and Claude Bernard supports the entire physiology of the sympathetic in its relations with the eye. The individual designation of the secretory nerves is due to the work by Dastre and Morat in 1878 and studies showing their autonomy and functional individuality were made by Heidenhain. It evidently remains to define the nature of the profound causes which may precipitate hypersympathicotony, but the foregoing suffices at least to render homage to the theory of "secretory neurosis" suggested by Donders with reference to glaucoma.

2. The alteration in the evacuation of the ocular liquids from the corneo-scleral shell becomes added more or less rapidly to the condition of hypersecretion, often occurring during the first stages of the disease.

If Chinese ink be injected experimentally into the eye of a laboratory animal, it may be recovered from Fontana's spaces. Aided by the Gullstrand illumination, Koeppe has been able to view "dust-like particles" accumulated during glaucomatous crises, but Knies has the merit of being the first to point out the important and constant feature of the blocking of the excretory pathways.

3. Secondary trophic disturbances affecting the vessels of the retina and involving the optic nerve add new complications, in varying degrees. These complications result from a vitiated hydrostatic condition and are beyond the control of the mechanism regulating the intra-ocular circulation. All causes which favour vascular sclerosis, especially syphilis and senility, constitute aggravating factors in the progress of these trophic disturbances secondary to hypertension occurring in a closed chamber, which finally produce optic atrophy and the papillary excavation of Schnabel.

In brief, though from the viewpoint of general pathology there still remain in the pathogeny of glaucoma certain obscure points referring to the true causes of the sympatheticotonic disturbances, the metabolic changes and the liquid exchanges, one fact is shown by clinical observation, namely, that glaucoma is related to nervous, organic, psychic and doubtless humoral instability, and to a so-called diathesis. It has the characters of an "essential disease," whose effects vary according to defective functioning which is individual, congenital or acquired with advancing age, 
the variations constituting factors which have great influence upon the course of the disease. Of its factors, standing in the order of their importance, hypertension occupies the first place and the therapeutic problem is to prevent vitiation of the liquid exchanges by medical treatment or to avert, by surgical measures, the retention of liquids which is fatal for the neuro-retinal structures.

\section{III.-Treatment and its results}

(a) Indications.- - It is but logical to attempt to render the diseased organism normal by medical treatment. Action becomes but hypothetical, however, if the circulatory disturbances considered essential factors of the glaucomatous condition are combated by medical treatment. Realities are departed from if medical treatment be opposed to operative measures.

Medical treatment is sometimes capable of retarding the course of the affection, of relieving certain prodromal signs of glaucoma and of rendering grave intermittent exacerbations less frequent. Such treatment includes good correction of ametropia, especially inverse astigmatism (Javal), attention to algetic states in the vicinity (facial and trigeminal nerves), study of the oculo-ocular reflexes, medication regulating sympathetic imbalance (eserine salicylate, gardenal or luminal, and opotherapy), treatment with calcium chloride or iodides, cardio-vascular tonics, correction of hyperglycaemia and antisyphilitic medication. It is necessary to utilise all these measures because they have an unquestionable influence upon the course of the disease, provided the action of miotics be never arrested. Pilocarpine is the sole medicinal agent whose efficacy and mechanism are truly comparable to those of surgical fistulization.

However, are not the successes obtained with medical treatment alone unusual, as indicated by the publication of almost every case in which medical treatment appears wholly sufficient? It was in view of this very probability that I devoted prolonged study ${ }^{6}$ to a case of chronic glaucoma presenting grave intermittent crises and occurring in a girl in accord with the menstrual cycle. Here I noted the action of opotherapy, completed my observation by indicating the cure of ocular hypertension during pregnancy and eventually pointed out various signs of humoral imbalance which replaced in this case the glaucomatous attacks, these signs consisting of crises of anguish, urticaria and paroxysmal tachycardia, the Raynaud syndrome and other signs of similar nature. All of these facts lie within the field of the clinical forms of hypertension, whose characters I have sketched for showing what it is proper to express concerning the efficacy of medical treatment. 
For guidance, it is necessary to make a choice among the symptoms which occur. Points guiding toward truly active therapy should be simple, clear and based upon the principal elements in the pathological syndrome. Persistence of a physiologically altered mechanism is shown by tonometry. Measurement of the central visual acuity and perimetry show the extent of existing lesions and their progressive tendency. How is it possible for surgery to be imprudent and inadvisable if the following conditions exist in spite of medical treatment?

1. Decline in central visual acuity.

2. Failure of the ocular tension to become normal ( 20 with the Schiötz tonometer).

3. Progressing alteration in the visual field, either in the paracentral zone of Bjerrum, or through nasal or inferior peripheral narrowing.

These three cardinal points must be thoroughly verified by examinations made methodically and periodically. Fluctuations in tension, narrowing of the visual field and declining visual acuity have the same significance. Any single one of these signs suffices in itself to prove that the disease is progressive and menacing, that it cannot be combated by medication designed to modify miopragia (as in syphilis, sclerosis, etc.), although such medication is important biologically but of secondary value from the practical viewpoint, and that it cannot be reached by the exclusive use of miotics.

Surgical treatment, though reaching only the hypertensive syndrome, is a measure of prudence and the only palliative one of permanent and durable efficacy, for the idea that hypertension in the eyeball presides over all the ocular signs of glaucoma remains still good.

Now, what surgical treatment is appropriate?

In acute glaucoma, the value of iridectomy is unquestionable. von Graefe has placed a curative procedure in our hands which renders his name immortal. In chronic glaucoma, the value of iridectomy has been tested and de Wecker, in a report presented to the French Ophthalmological Society in 1901, has shown the results of a memorable inquiry addressed to all the well-known contemporaries, who replied that iridectomy, like all other operations employed at that time (such as puncture or sclerotomy), is very disappointing in chronic glaucoma.

Solution of the problem of durable fistulization of the eye and establishment of the principle of action and the site of election were the innovations provided by subconjunctival and limbic sclerectomy, or fistulization of the eye as obtained by the subconjunctival resection at the scleral limbus of a fragment of the 
ocular shell (Felix Lagrange, 1905). ${ }^{7}$ Amongst the numerous operators who have more lately devised instruments and technique for individual performance of subconjunctival and limbic sclerectomy, Elliot is surely the one who has done most to popularise the operation of Felix Lagrange, especially through his personal dexterity with the trephine. The question of operative technique is the one which I propose to stress to-day.

(b) Technique -Eleven years ago I indicated, ${ }^{8}$ in the Annales d'Oculistique for September, 1926, the operative procedure which I prefer. I gave the details of instrumentation and a schematic plan of the operative stages of the original technique upon which the method of subconjunctival and limbic fistulization is based, and whose principle I' most piously continue to observe, since I have daily occasion to admire its incomparable efficacy. Now, what is the best form of knife?

The blade should be narrow and thin, but not flexible, in order tci work in the irido-corneal angle. Effacement of the anterior chamber often so narrows the passage for the knife that I am inclined to doubt whether the angie is actually incised at its apex when the anterior chamber is entered, as in glaucoma. The Nicati knife is good, but the sclerotome obtainable from good makers is better. It is shown here in the natural size. The blade is short and narrow, the tip fine and the back wide. The breadth of the back is absolutely necessary for the puncture of certain especially rigid sclerotics (Fig. 1).

FIG. 1.

The knife is held in the right hand, a fixation forceps in the left hand. The eye is immobilised, lightly but firmly, by grasping it near the limbus, near seven o'clock for the right eye (Fig. 3).

It is grasped near five o'clock for the left eye (Fig. 4), because when so placed the left hand can more readily orient the eyeball and fix it on the tip of the knife at the moment of counter-puncture and upon the knife-edge when the flap is cut.

What is the site of puncture? In replying, it may be recalled that there is an average distance above of 1.75 millimetres between the apex of the irido-corneal angle and the limbic limit of the separable part of the conjunctiva. This zone is that where the cornea is held by the sclerotic, as a bevelled watch-glass might be held. The corneal bevel is nearly 1 millimetre high. The scleral 


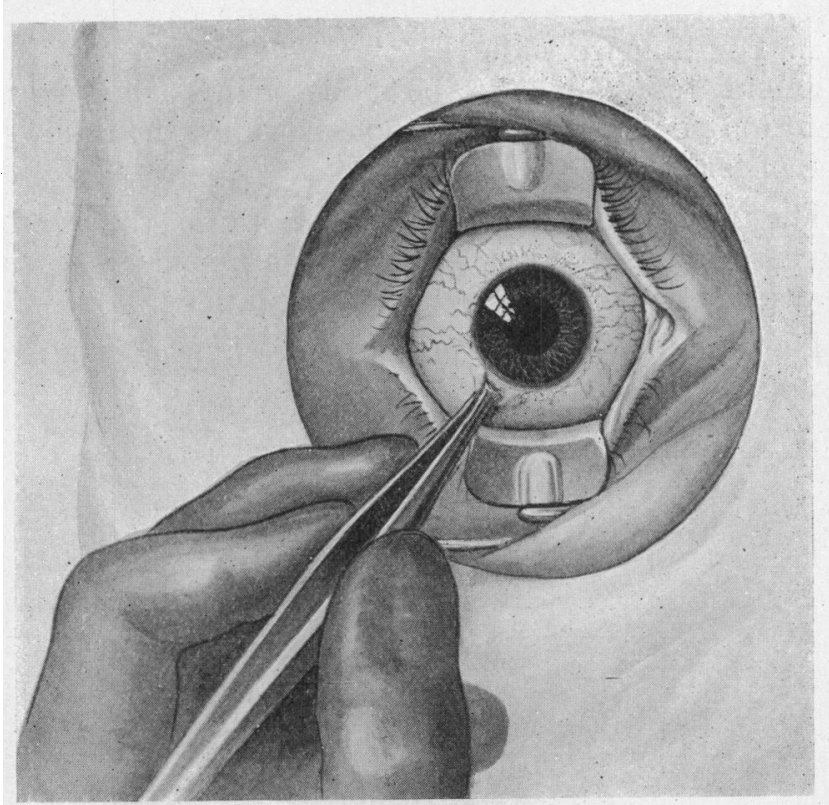

F1G. 3. Right eye.

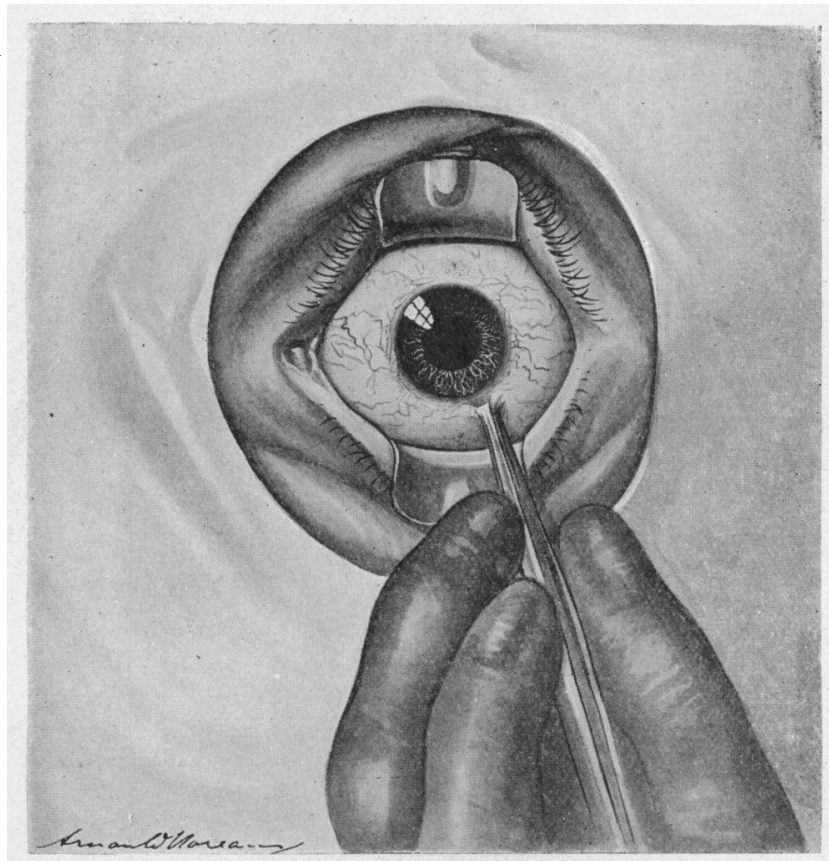

FIG. 4. Left eye. 
portion present at the apex of the irido-corneal angle is therefore less than 1 millimetre wide (Fig. 2).

The scleral resection must be made at this site. In order that the operation may be useful and not injurious, the following points must be observed.-

1. The tissue excised should consist only of the sclerotic, without any corneal tissue at the base of the flap, since the corneal tissue proliferates and obstructs the scleral orifice.

2. The ciliary body must not be injured, because it is the hilum of the eye.

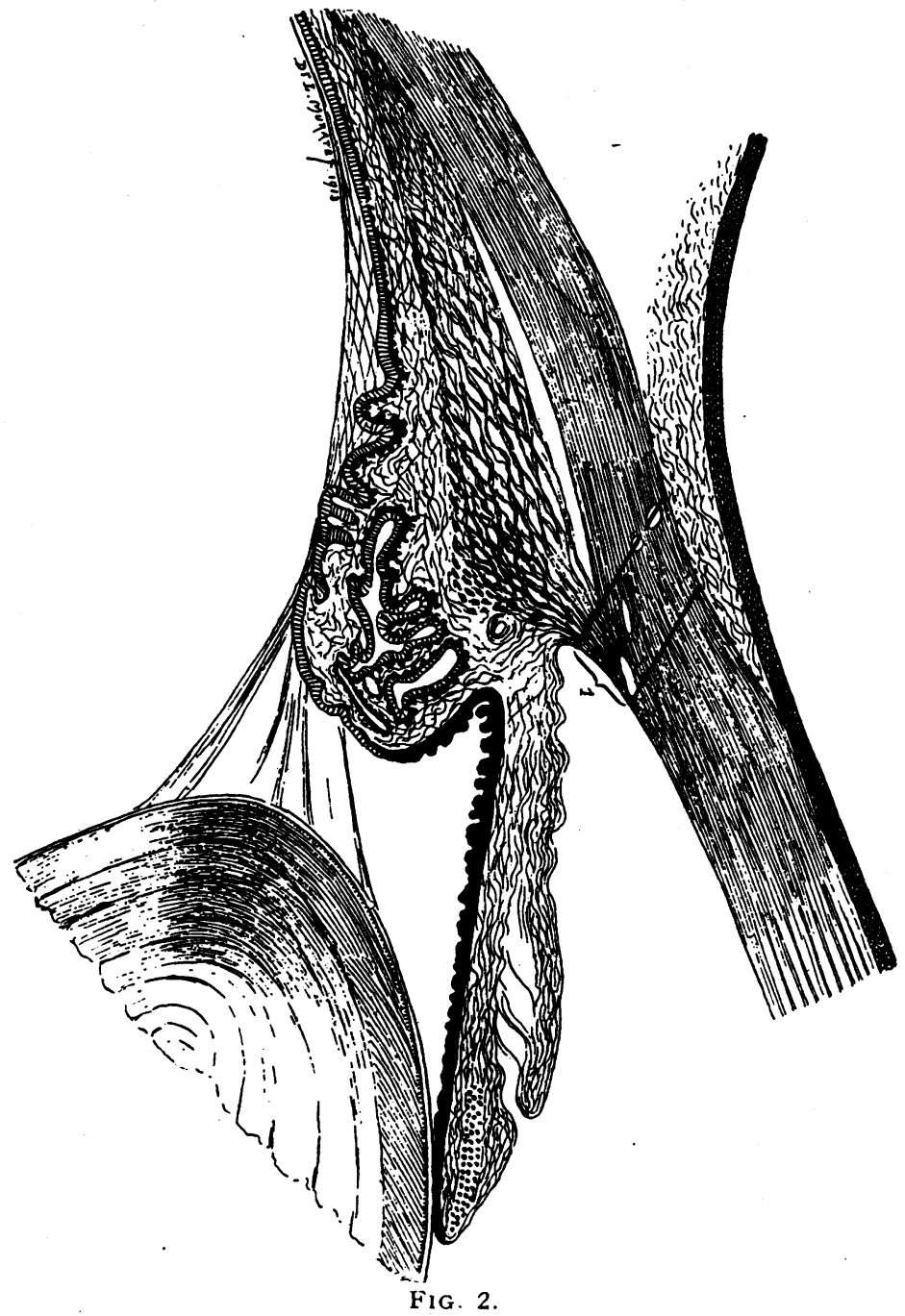


3. The incision should not be wide enough to permit the vitreous to escape.

If operating on the left, for example, puncture should be made near the one o'clock point, about 2 millimetres behind the limbus and thus in purely sclerotic tissue. The tip of the knife should be advanced toward the anterior chamber, the centre of the pupillary orifice serving as the point of direction. The knife-edge

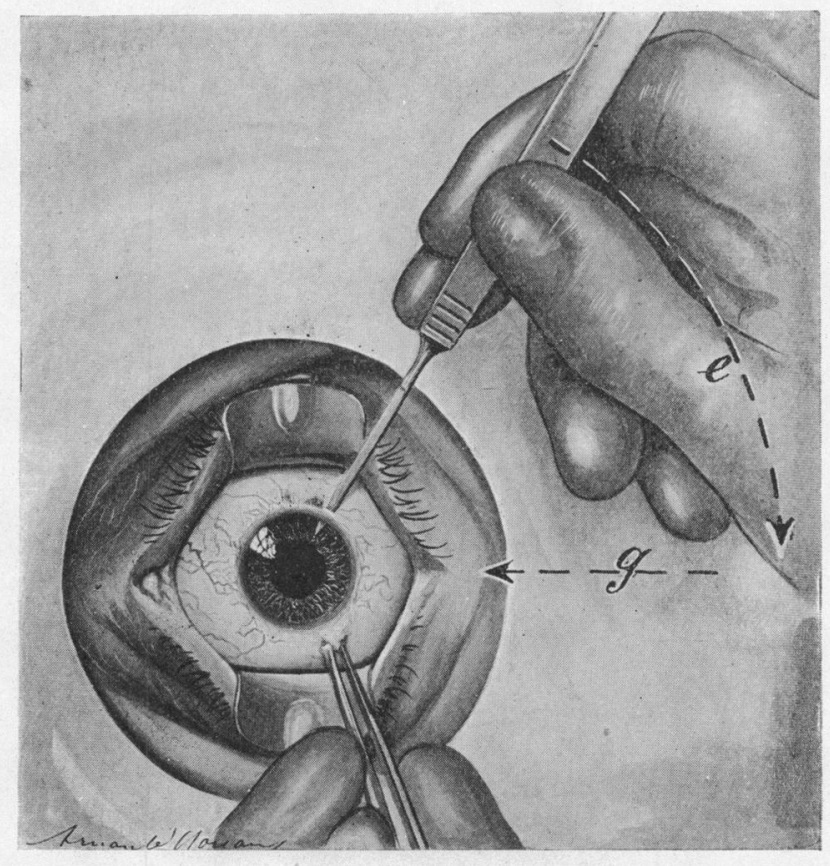

FIG. 5. Left eye

is directed toward the sagittal axis of the eyeball and its flat side lies in a frontal plane. The knife is stopped as soon as its tip is visible in the irido-corneal angle and can work freely there (Fig 5). In this way the height of the scleral flap and the inclination required for forming it are quickly determined.

If the anterior chamber is effaced, as frequently happens in glaucoma, the handle of the knife must be lowered as soon as the knife appears in the anterior chamber, without engaging the tip as deeply as appears in Fig. 5 .

The knife must now be turned. The back of the knife is supported as on a fulcrum and placed in line with an axis perpendicular to the sagittal axis of the cornea by slipping it into the irido-corneal angle as into a sheath, below the projection formed 
by the scleral bevel. The flat posterior surface of the sclerotome is thus, so to speak, placed upon the iris, while the edge is at the bottom of the irido-corneal angle which it gently touches before sectioning the tendon of the ciliary muscle. It is now only necessary to push the knife in this same direction, the left hand remaining firmly fixed, in order to make a counter-puncture at a point symmetrical with that where the original puncture was made

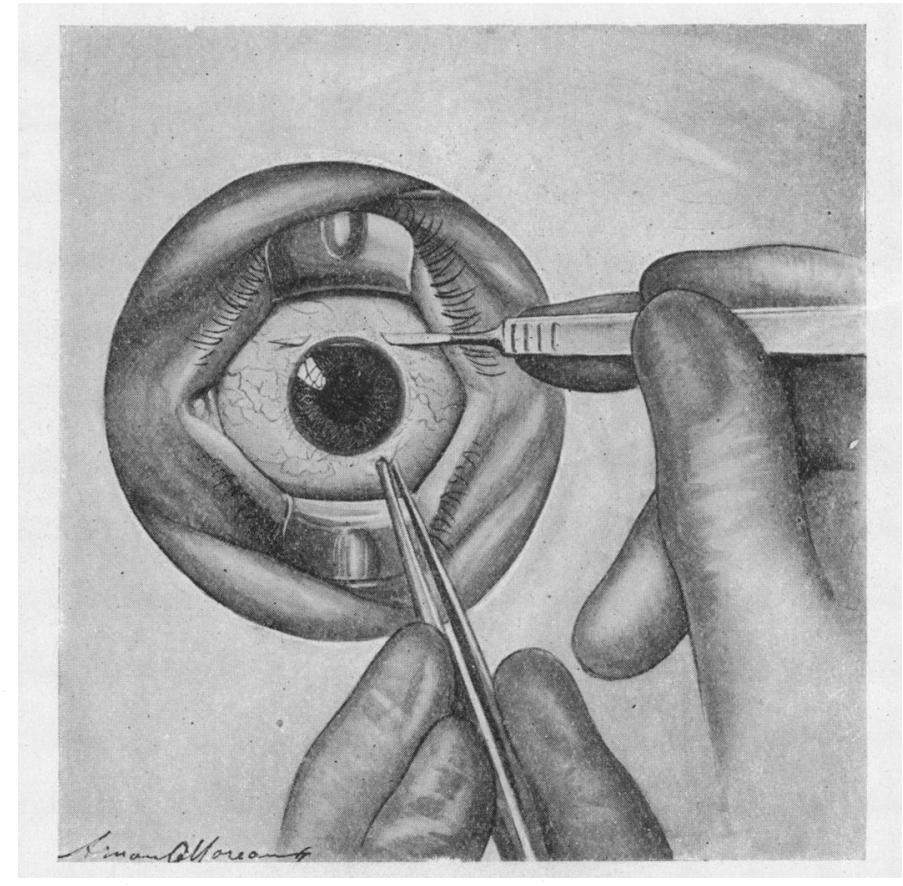

FIG. 6. Left eye.

(Fig. 6). Should the counter-puncture be made at the limbus, for fear of emerging too far backward, the result is of no importance, as we shall see.

A moment for halting has now arrived. The anterior chamber is punctured and counter-punctured and must be allowed to empty itself slowly, the more gently in proportion to the hardness of the eyeball and with the patience necessary for doing good work. The subconjunctival spaces become oedematous and it will be presently impossible not to dissect out a good conjunctival flap.

When this brief stage of arrest is completed, the scleral flap is formed by a slight sawing movement. The scleral wound now gapes, its lower lip constituting the apex of a flap whose height 
has just been determined by the position of the puncture. This line of incision in the sclerotic makes an incurved sweep above the limbus which is parallel to the latter if the counter-puncture has been symmetrical (Fig. 7), and less parallel if the counterpuncture was made at the limbus (Fig. 8). However, the scleral crescent is always high enough because its height was determined by the site of puncture made in the first stage of the operation.

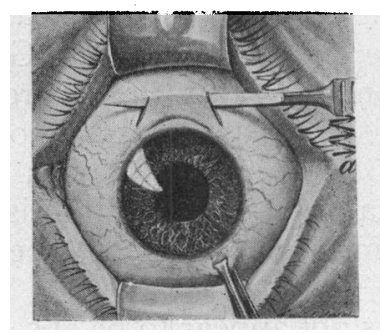

FIG. 7.

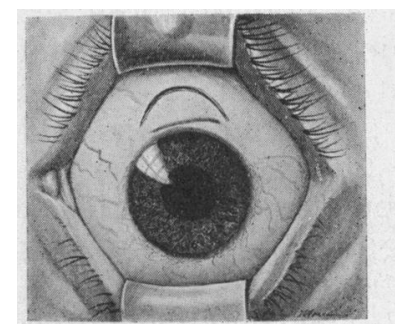

FIG. 8.

It is now only necessary to form slowly a conjunctival flap and to lift it with an iris forceps in order to resect beneath it one fragment or more of the sclerotic. These fragments are narrow and removed in a direction parallel to the limbus with the punch of the modified Vacher type (Fig 9). This Vacher punch is intended for resection of the iris and cannot section the sclerotic.

Sclerectomy as thus performed is easily completed by peripheral or total iridectomy. It is not ill-timed to stress this completion

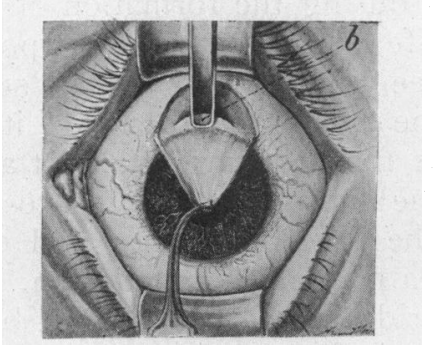

FIG. 9.

for, though scleral iridectomy as devised by von Graefe is a classical procedure, it has certain details in this case which depend upon the form and the supralimbic site of the scleral flap, which is exclusively scleral. These points distinguish it from the effect obtained with the corneo-scleral incision of von Graefe. 1. Iridectomy is a classical procedure in acute glaucoma. 2. It is not indispensable in some forms of chronic glaucoma. 3. Iridectomy may be performed by simultaneous section of the scleral crescent, 
between the same jaws of the forceps. 4. Care should be taken to grasp the iris without groping for it in the anterior chamber. 5. If iridectomy is not done, the only thing risked is a wellprotected subconjunctival strangulation of the iris, or iridencleisis. Such are the points which I wish to stress.

(a) The beneficial effects of the von Graefe iridectomy are never absent from the mind in all treatment undertaken for combating glaucoma. Although the results obtained with simple sclerectomy, and still more so those secured by iridectomy done in cases of chronic glaucoma not relieved by the iridectomy of von Graefe, permit iridectomy to be separated from the other procedure concerning the indications and principles, it is prudent to do both while the patient is on the table. Besides, iridectomy is really the complement of sclerectomy, because it avoids the risks of strangulation and thus greatly simplifies the post-operative conditions.

(b) The von Graefe iridectomy does not appear to be absolutely necessary in chronic glaucoma for the reasons which I have indicated and also in cases where the iris is atrophied. Atrophy of the iris occurs frequently in senile glaucoma and the partial " sympathectomy" practically constituted by antiglaucomatous iridectomy is no longer justifiable here because it can deal only with degenerated tissue.

Still another circumstance should cause the operator to desist from devoting an entire operative stage to frank resection of the iris with the cutting forceps. It consists of the partial iridectomy which is sometimes effected involuntarily, when the pectinate ligament is divided during the formation of the scleral flap. At this moment the knife is fixed between the points of puncture and counter-puncture (see Fig. 6) and its flat surface lies upon the anterior aspect of the iris. On account of its location, the knife cannot fail to divide the pectinate ligament and thus open access to the margin of the supra-choroidal space of Schwalbe, but it thus also touches the base of the iris and carries away a short fragment in the area of the scleral incision.

This part of the irido-corneal angle must be carefully inspected before entering the iris forceps toward the anterior chamber, for it has occurred that an orifice has been made at the base of the iris through which the iris forceps or hook might be caught and injure the lens. As a matter of fact, experience and habit permit one to perceive the possibility of such a breach in the iris and to note, before verifying the fact, that the knife has made a "peripheral iridian opening in the angulo-cameral region." and that there is no need to complete the iridectomy. When the iris is intact, it becomes almost always prolapsed during the manipulations of the scleral resection and thus becomes engaged in the scleral incision, as shown in Figs. 10, 11 and 12. 

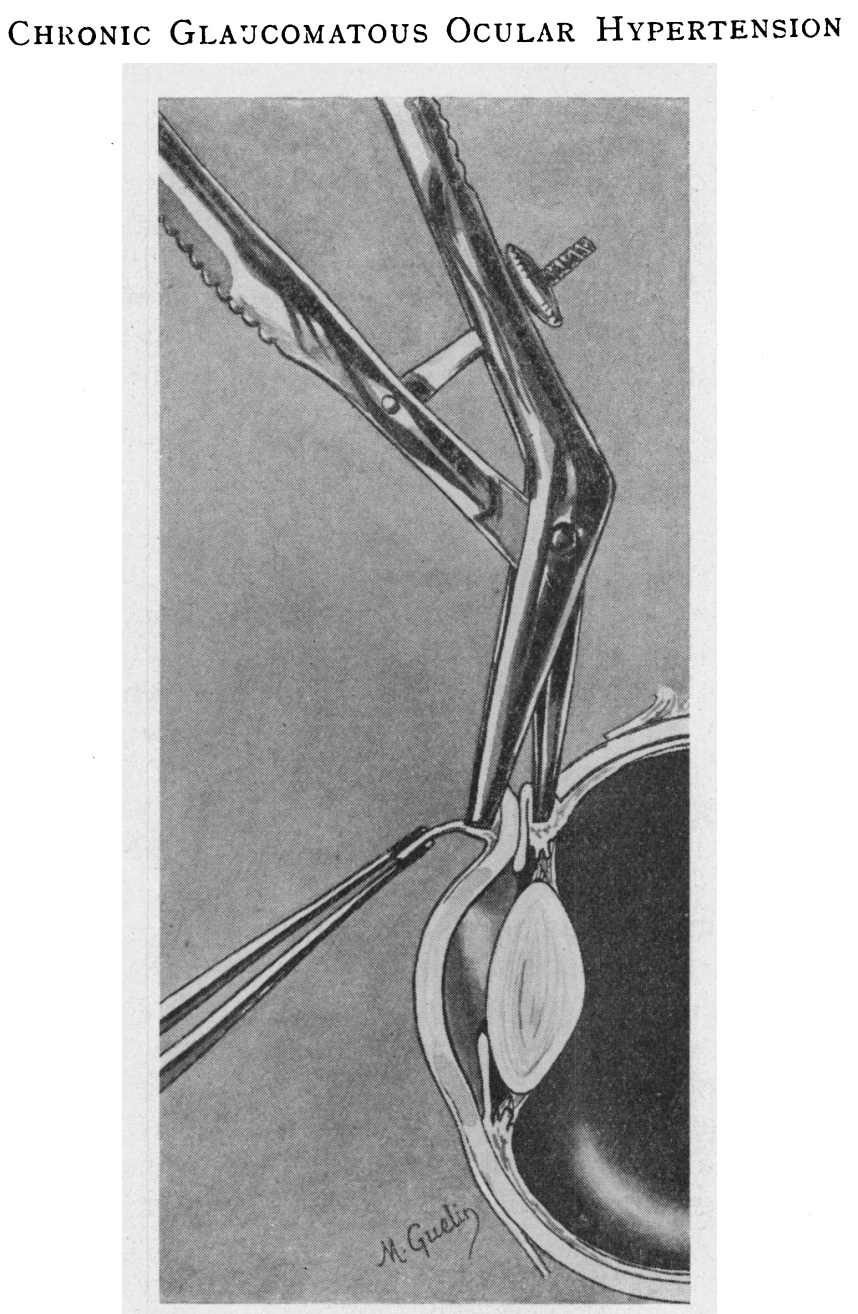

FIG. 11.
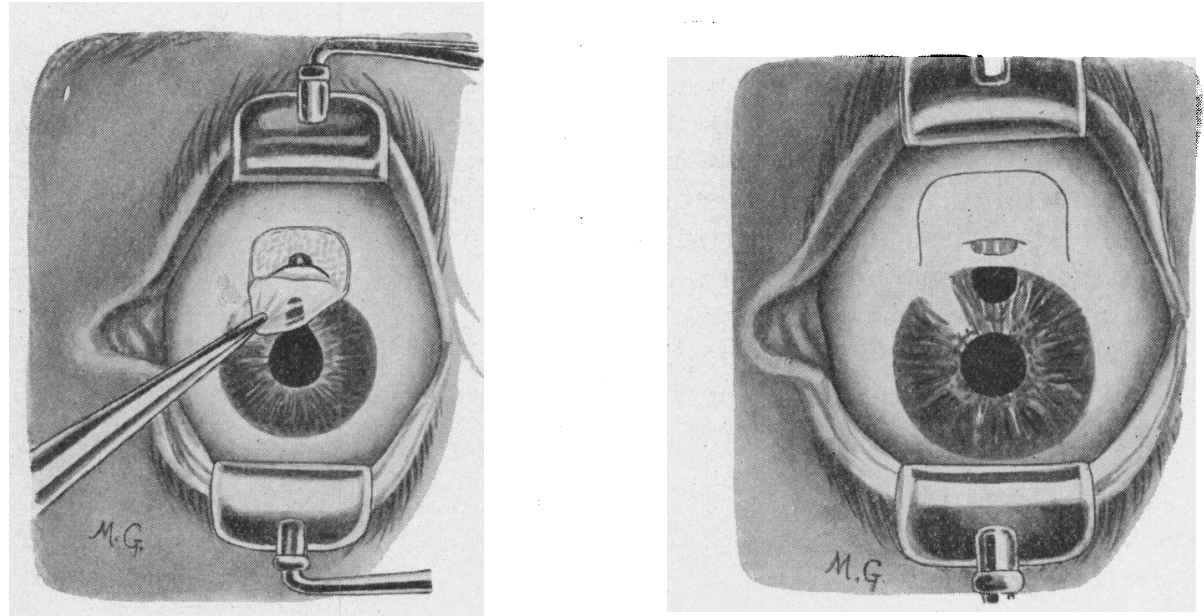

FIG. 10.

FIG. 12.

Drawings from life by Dr. Guélin.

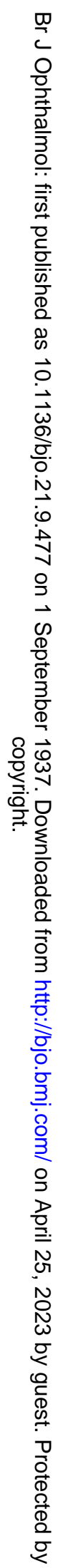


(c) In half the cases, iridectomy may be done along with sclerectomy. The iris becomes engaged in the scleral wound as a tiny black ball at the moment when traction upon the conjunctival flap places the scleral crescent and the subconjunctival tracts between the jaws of the punch which are to remove them (Fig. 10). Under these conditions, the punch removes both the iridian prolapse and the scleral crescent, together with its subconjunctival attachments (Fig. 11). A drop of the aqueous humour escapes simultaneously with the contraction of the iris sphincter which has not been sectioned and reveals a more or less wide peripheral iridectomy, completely accomplished at the site of election (Fig. 12). The iridectomy thus obtained may be total, in which case the result is entirely satisfactory.

(d) When the iris is not thus frankly strangulated in the scleral incision and thus favours iridosclerectomy, occurring at the actual performance of sclerectomy, it is necessary to make sure, before inserting the iris forceps or hook into the space formed by the scleral resection, as I have remarked, that the knife has not clipped off during its passage a bit from the base of the iris when the pectinate ligament is divided. It is also necessary to make sure that the iridian prolapse, which would occur so opportunely before the operative stage devoted to scleral resection, does not occur afterward under the action of pressure inevitably made upon the eyeball during the manipulations. The iris forceps can easily grasp, at the bottom of the space formed by the scleral resection, a small iridian prolapse without engaging in the anterior chamber for grasping the iris with the object of doing an iridectomy.

(e) The operator may be prevented from combining iridectomy with sclerectomy through bleeding or because of lack of co-operation on the part of the patient. In such an event, post-operative strangulation might very probably be avoided by instilling eserine after operation, but should it not be avoided the sclerectomy performed would be accompanied by iridencleisis. This result is not very regrettable, especially if care be observed to release the subconjunctival and adherent iridian prolapse three days after the sclerectomy. Local anæsthesia is very carefully instituted and then, by dissection, the conjunctival flap covering the space left by sclerectomy and the strangulated iris within it is raised. The dome of the strangulation is then gently touched and incised with the knife. There is no need to suture the conjunctival flap thus dissected at the site of the iridian prolapse, nor should the galvanocautery be applied to the prolapse, since cauterisation closes fistulae.

I have presented these points, and especially this latter detail, in order to show that failure to accomplish a sclerecto-iridectomy 
as just described doès not necessarily militate against a useful result. I desire also to point out how this operation associates in a synthetic way successive procedures which have all been accepted by competent operators.

1. First, puncture is performed and then completed by sclerotomy, as devised by de Wecker, which may be further supplemented by the scleral iridectomy of von Graefe.

2. Fistulisation, the real and original object, is obtained by simple scleral resection at a site physiologically adapted to it.

3. Iridectomy is associated with it because it is classical and easy. If it is not done, a post-operative iridian strangulation may be resected, but such a subconjunctival iridian strangulation, if well covered, adds to the operation of Felix Lagrange the essential character of iridencleisis, a procedure which has its adherents. I do not advise this, but if an iridian strangulation is formed after simple sclerectomy, it is necessary, as soon as the strangulation has been completely formed, and is well adherent, to dissect the conjunctiva and then open the dome of the iridian prolapse. In this way the strangulated and adherent portion of the iris may help to serve as an endothelial sheath for the fistulous scleral orifice.

The operation is thus easy, clearly marked and rendered as external as possible and one which the beginner may terminate at any of its stages with the consolation of having at all events done a classical anti-glaucoma operation. Puncture, sclerotomy, iridectomy and even accidental iridencleisis, such are the stages, and the only risk incurred by an operation which never directs the axis and weight of an instrument toward the ciliary body, which is entirely performed at the apex of the cameral angle through an incision so small that nothing can become engaged in it save the iris, and so well placed that there is no risk of a corneal resection, which could only be an ineffective and poorly defended caricature of the scleral resection. "Do not touch the cornea, for it proliferates, and do not touch the ciliary body, for it is resentful"-such is the verbal tradition inspiring this description.

The fistulising treatment may thus be accomplished by three operative methods, namely, simple limbic sclerectomy, sclerectomy with peripheral iridian opening, and sclerecto-iridectomy.

(c) Results.-From results recorded statistically which refer only to cases actually operated upon and followed up for at least one year, the conclusion is sincerely warranted that the fistulising method succeeds in 85 per cent. of the cases in chronic glaucoma, while iridectomy yields an average of 25 to 30 successes per hundred, according to the best statistics.

Rather than depending upon personal records of a single operator and a uniform technique, the recent thesis by E. Joseph ${ }^{9}$ should 
be consulted, entitled "The remote results of anti-glaucomatous operations." This thesis presents the results obtained in various major hospital services by different surgeons of differing experience and offers the following conclusion: "When medical treatment fails to render the tension normal and to prevent even the siightest diminution of the functional value of the eye, it is necessary to employ sclerecto-iridectomy and operate as promptly as possible, however the risual functions be affected at this time."

It is important to devote special attention to the failures, since they supply the most instructive facts.

Operative accidents are negligible. The technique of subconjunctival and limbic scleral resection, if the precaution is observed to avoid previous dissection of the conjunctiva, which should be respected because it is the only covering of the scleral orifice, does not risk early or late infection, which has occurred following trepanation done with the instruments devised by other operators for the operation of Felix Lagrange. Personally, I never have late infection of the scar.

True and really unavoidable failures, whose percentages are of 5,10 or 15 according to the results recorded by different writers, are due to lesions in vessels of the retina or in the optic nerve which are degenerative and whose progress cannot be stayed when decompression is accomplished too late. If delayed for too long a time, restoration of the normal ocular tension and tonus may be powerless to arrest progressing optic atrophy.

Here may be grouped the cases in which the patient presents good or excellent visual acuity (often monocular) and a visual field whose nasal or inferior limit lies close to the fixation point. In such cases, the condition which menaces the fixation point cannot remain stationary if the ocular tension remains high, or perhaps even if it be rendered normal. When miotics prove insufficient under these conditions, the rule is to take the chances and operate. It is necessary, however, to inform the patient or those who are responsible, that operation is thus undertaken as a last resort, that it risks marked contraction of the visual field with destruction of central vision, and that it may therefore fail.

The good results have been so frequent that they have reversed the statistics and given 80 per cent. to 90 per cent. success instead of a corresponding proportion of failure. They are likewise instructive and lead to the same conclusion that "it is necessary to operate without delay in cases of glaucoma in which medical treatment fails to reduce the ocular tension to normal limits and operation is necessary even if the medical treatment does reduce the tension to normal should alteration of the visual field progress in the slightest degree or should visual acuity decline." 
Felix Lagrange announced his method on June 8, 1905, at a meeting of the Society of Medicine of Bordeaux. In October, 1905, he described, at the French Congress on Surgery, a " new procedure for the treatment of chronic glaucoma by the formation of a filtering scar," basing his paper on the results obtained in fifteen cases treated by this method. " One of these cases," he stated, " was operated upon two years ago (in 1903) and two others were treated eight months ago." The thirty-third anniversary of this discovery has now arrived, and I have thought that it might be of interest to recall, on this occasion, the principles of a surgical method so largely honoured by time, and to give the details of our present technique, notably because the latter has preserved all the features claimed to be essential at the earlier period and has proved and tested the soundness of their physiological and physiopathological basis. ${ }^{10}$

\section{REFERENCES}

1. Lagrange, Henri.-Douleurs viscérales. Sommation Glaucomateuse. Bull. de la Soc. d'ophtal. de Paris, p. 179, 19 Mars, 1932.

2. Beauvieux et Delorme.-Etude sur le sens lumineux chez les glaucomateux. Arch. d'ophtal., Février, 1913.

3. Delorme.-Des scotomes paracentraux dans le glaucome chronique. Arch. d'Ophtal., Août, 1919.

4. Lagrange, Felix, et Beauvieux.-Anatomie pathologique et pathogénie de l'excavation glaucomateuse. Arch.d'Ophtal., p. 129, 1925.

5 Lagrange, Felix.-Epitheliomas et Carcinomes primitifs des procès et du corps ciliaires. In traité des tumeurs de l'oeil, tome I, p. 724 et suivantes, G. Steinheil Ed., 1901.

6. Lagrange, Henry.-Glaucome et troubles endocriniens. Presse Médicale, Masson Ed., 5 Avril, 1924.

Derangements of the orgnao-vegetative nervous system in essential glaucoma. Brit. Jl. of Ophthal., August, 1925.

7. Lagrange, Felix.-De l'Iridectomie suivie de la Sclerectomie dans la cure du Glaucome. Soc. de Médecine de Bordeaux, 8 Juin, 1905.

Traitement du Glaucome chronique par l'établissement d'une cicatrice filtrante. Description d'un procédé nouveau. Congrés français de Chirurgie, Octobre, 1905.

De l'iridectomie et de la Sclerectomie combinées dans le traitement du Glaucome chronique. Soc. Frang. d'Ophtal., Mai, 1906.

Traitement du Glaucome chronique par l'iridectomie et la Sclerectomie combinées. Arch. d'Ophtal., p. 439, 1907.

De la cicatrice filtrante dans la cure du Glaucome.-Variétés de cette cicatrice après l'iridectomie et la Sclerectomie combinées. Arch. d. Ophtal., p. 65, 1908.

De la Sclerectomie simple dans le Glaucome chronique simple. Arch. d'Ophtal., p. 408, 1908.

De la valeur de la Sclerectomie dans le traitement du Glaucome chronique. Arch. d'Ophtal., p. 673, 1908.

De la fistulisation de l'oeil. Arch. d'Ophtal., p. 138, 1909.

Indication et valeur comparée de la Sclerectomie perforante : sans iridectomie, avec Iridectomie. Arch. d'Ophtal., p. 529, 1910.

De la Sclerectomie avec boutonnière iridienne périphérique. Arch.d'Ophtul., p. $433,1911$.

Opération pour le Glaucome specialement au point de vue des résultats comparitifs obtenus par l'Iridectomie et ses substitutions récentes. Rapport au Congrès international d'Ophtal., Londres, 1913. 
7. Lagrange, Felix.-De la méthode fistulisante dans la cure du Glaucome Chronique. Valeur comparée des divers procédés opératoires. Arch. d'Ophtal., Février, 1914.

Des opérations décompressives dans le traitement du Glaucome Chronique. Arch. d'Ophtal., Novembre, 1920.

8. Lagrange, Henry - Petits détails de technique concernant la Sclerectomie limbique faite au couteau. Ann. d'Ocul., Tome CLXIII, p.' 695, Septembre, 1926.

9. Joseph, Etienne.-Resultats éloignés des opérations antiglaucomateuses. Thèse de Paris, 1935.

10. Lagrange, Felix.-Du Glaucome et de 1'Hypotonie. G. Doin et Cie Ed., Paris, 1922.

\section{THE USE OF RADON IN THE TREATMENT OF METASTATIC CARCINOMA OF THE CHOROID}

BY

\section{P. JAMESON Evans \\ BIRM INGHA M}

THE case described is unusual in the development of metastatic carcinoma, secondary to that of the breast, in both eyes, in the one two months before the other. The first eye was excised, the fellow eye at that time being normal, and the second treated by the application of radon seeds.

N.D., aged 41 years, female, first attended the Birmingham and Midland Eye Hospital complaining of a foreign body in the left eye on December 16, 1935, when vision was: R. 6/6, L. 6/9. (i) There was some conjunctivitis of the left eye but no foreign body was found. On January 6,1936 , the patient complained of defective left vision of about ten days duration, and was found to have (LV) less than 6/60. A pale exudate was seen in the fundus of the left eye situated to the nasal side of the disc, extending from the disc outwards. This continued to increase slowly in size

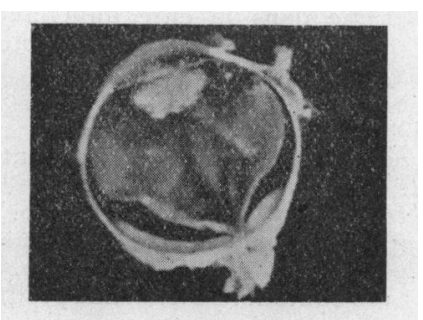

FiG. 1

Choroid of Left Eye. 